\title{
What moderates the attainment gap? The effects of social identity incompatibility and practical incompatibility on the performance of students who are or are not Black, Asian or Minority Ethnic
}

\author{
Daniel Frings ${ }^{1}(1) \cdot$ Ilka H. Gleibs $^{2} \cdot$ Anne M. Ridley $^{1}$
}

Received: 24 August 2018 / Accepted: 10 October 2019 / Published online: 6 November 2019

(c) The Author(s) 2019

\begin{abstract}
A successful journey through higher education is, for many, a once in a lifetime opportunity for social mobility. Unfortunately, one notable feature of higher education systems is that students from some backgrounds do not achieve the same academic attainments as do others. The current study tests the role of one particular set of processes: social identity (in)compatibility on academic performance. Participants were recruited at two time points from a pool of first year undergraduates at a modern London University $(N=215)$ of which $40.1 \%$ were classed as Black, Asian or Minority Ethnic (BAME), 57.1\% as non-BAME and $2.8 \%$ did not provide this information. A prospective design was employed: Alongside demographic data, measures at the start of the academic year consisted of measures of student and ethnic identity, and both practical and identity incompatibility. At the end of the academic year, average marks achieved were gained for each student from the university's registry system. Results indicate that BAME students had equal levels of student identity to non-BAME students, but higher levels of ethnic identity. They also typically experienced higher levels of both practical and identity incompatibility. Finally, BAME students had lower attainment than did non-BAME students. Both practical and identity incompatibility appeared to moderate this effect. However, contrary to predictions, it was only under conditions of low and medium levels of incompatibility that BAME students attained lower marks than their non-BAME peers. The theoretical and practical implications of these findings are discussed.
\end{abstract}

Keywords Education $\cdot$ Social identity $\cdot$ Incompatibility $\cdot$ Attainment $\cdot$ Social mobility $\cdot \mathrm{BAME} \cdot \mathrm{BME} \cdot$ Ethnicity

Daniel Frings

fringsd@1sbu.ac.uk

1 Division of Psychology, London South Bank University, London, UK

2 Department of Psychological and Behavioral Science, London School of Economics, London, UK 


\section{Introduction}

A successful journey through higher education is, for many, a once in a lifetime opportunity for social mobility. Unfortunately, one notable feature of many higher education systems is that students from some backgrounds do not achieve the same academic attainments as do others. In the UK, at risk demographics include older students, those from lower social economic status (SES) backgrounds and members of some ethnic minorities (Broeke and Nicholls 2007; Jetten et al. 2008; Labi 2015; Mok et al. 2016, 2017; Murtagh et al. 2016; Reay et al. 2002; Richardson 2012; Ridley 2007; Woolf et al. 2013) and there is also some evidence that lower attainment in Black, Asian or Minority Ethnic (BAME) students compared to white students is greater when they are part-time, older, and female (Richardson 2008). Similar attainment gaps have been observed in other areas of the world, such as wider Europe and the US (see Heath et al. 2008; Schnell and Azzolini 2015; Stevenson and Whelan 2013, but cf. Hermansen 2016 for example of an exception).

Many studies have explored other factors that may underpin academic performance differences between BAME and non-BAME students. For example, studies exploring differences in approaches to learning as a function of ethnic group and the impact on assessment have produced mixed results (Martiny et al. 2015; Mpofu and Oakland 2001; Ridley 2007). It is argued that the assessment environment is likely to produce stereotype threat which increases anxiety, thereby reducing cognitive capacity, attention, etc. (e.g. Steele 1992, 1997). For instance, Osborne (2001) found evidence that white high school students experienced lower levels of self-reported anxiety following academic tests, and that controlling for anxiety reduced observed differences in attainment between non-BAME and BAME groups.

However, little research has addressed the impact of joining a university from the perspective of life transitions, and the effect this has on students' social identities (identities we have based on perceived memberships of social groups, see Tajfel and Turner 1979). The current study tests the role of one particular set of processes, social identity incompatibility (difficulties that arise as a result of differences between identities related to groups, see Ethier and Deaux 1994) on academic performance amongst BAME and non-BAME students. In particular, it looks at the extent that the attainment gap between BAME and non-BAME students is moderated by identity incompatibility. In doing so, the current paper also posits and tests a novel differentiation between types of incompatibility-namely practical incompatibility and identity incompatibility.

\subsection{Social identity, multiple identities and life-transitions}

Social identities are aspects of the self which relate to perceived memberships of social groups that an individual holds (see Tajfel and Turner 1979). Social identities can often be beneficial-recent research has highlighted the importance of social identities for outcomes such as health, adaptation to new situations and the experience of stress (e.g. Jetten et al. 2012). For example, strong social connections can reduce day to day experiences of occupational stress (Haslam and van Dick 2010; 
Haslam and O'Brien 2005), facilitate positive recovery from injury (Jones et al. 2011, 2012), better cognitive performance amongst the elderly (Gleibs et al. 2011a, b), better recovery outcomes for substance addicts (Frings and Albery 2015; 2016; Buckingham et al. 2013; Cruwys et al. 2014) and for those with depression (Cruwys et al. 2013) or recovering from life-changing surgery (Bule and Frings 2015). In relation to higher education, a strong identity as a student has been linked to a deep approach to learning (Bliuc et al. 2011).

\subsection{Identity (in)compatibility, transitions and attainment}

Individuals carry multiple identities which reflect different aspects of their lives (e.g. to do with work, spirituality, leisure activities, ethnicity, social connections, etc., see Tajfel and Turner 1979). These identities can be compatible with one another (e.g. share the same values, or not present pragmatic difficulties) or not. For instance, being a 'Counsellor' and a 'Christian' may be compatible, as they share the same values (e.g. compassion) and one may be able to meet the demands of both in day to day life (e.g. being able to attend work and collective worship). Being a 'Soldier and a 'Christian' may not-if the values (e.g. compassion) and demands (shooting and attitudes to pacifism, for example) conflict (see Héliot et al. 2019).

Alongside evidence pointing to the positive effects of social connections and single social identities, a growing body of research suggests that actively perceiving oneself as having multiple compatible identities may also be beneficial. For instance, raising awareness of multiple group memberships is associated with faster physiological recovery amongst novice athletes, and also greater resilience during a cold-pressor task (Jones and Jetten 2011) and buffers against negative stereotypes in sensorimotor tasks (Martiny et al. 2014). Multiple social identities have also been shown to improve quality of life (and physical health) amongst the elderly (Ysseldyk et al. 2013) and also appear to be of particular benefit during transitions between life stages (see Iyer et al. 2009) which can include, for example, company mergers, or joining a university as a new student (Amiot et al. 2012; Gleibs et al. 2008; Jetten et al. 2008). In such circumstances, multiple identities may buffer against the stresses of the transition by providing a sense of continuity and sources of social and practical support (Amiot et al. 2007, 2012). Identities that are incompatible may be less beneficial, or even detrimental. Research from a social identity perspective suggests transition to university and developing an identity as a student can negatively affect wellbeing and that this effect is mediated by perceived incompatibility (Iyer et al. 2009; Jetten et al. 2008). Identity incompatibility has also been shown to predict lower perceived readiness to attend university and lower expected identity with being a student (see Jetten et al. 2008). Thus, one moderator of the effects of multiple identities during phases of transition appears to be the extent to which existing identities are seen to be compatible or incompatible with those being adopted and suggests that this concept could explain the lower attainment of, for example, lower SES students in higher status universities.

One limit on existing research into incompatibility is the relatively short and indistinct measures used to assess it. For instance, in both Ethier and Deaux (1994) 
and Jetten et al. (2008), identity incompatibility was measured with three items (i.e. 'I'm afraid my present life is incompatible with my new identity as a university student', 'I cannot talk to my friends about what it will be like at university' and 'My family background is incompatible with university life') or using visual representations of overlap between identities (Jetten et al. 2008, Study 2). Whilst such measures capture identity incompatibility in a broad form, it is possible that the structure of this construct is more complex. For instance, incompatibility could be problematic on a practical level because it places demands on ones' resources or time (for instance, a religious identity may require one to be a certain place at certain times or a cultural identity may require siblings to engage in child care duties). In contrast (and as envisioned in extant literature) incompatibility could be due to identity related aspects-representing differences in norms (e.g. conflicts in moral values between one's identities), and common experience(s) which can be discussed with someone who holds one, but not both, identities. We here argue that these may be distinct types of incompatibility (which we label practical incompatibility and identity incompatibility respectively). We define practical incompatibility as 'behavioural or resource (including time) based demands or norms stemming from one identity which conflicts with those stemming from other identities'. We define identity incompatibility as 'value based norms stemming from one identity which conflict with another identity'. Whilst both are identity based, we perceive the former as having more impact on a practical day to day, situationally specific level, whilst the latter will have more impact on a psychological and interpersonal level. As such, we hypothesize that they may have differential effects on psychological well-being and also academic performance. Furthermore, these effects may vary at different stages of the identity transition. Given there is little literature disambiguating these two concepts, a key goal of the current study was to explore the extent to which these two dimensions firstly appear to be separate, and secondly the extent to which they differentially predict outcomes. A further (and perhaps more significant) limitation of the existing literature on incompatibility/life transitions is that the outcome data consists of psychological variables-even amongst longitudinal studies. Such literature often focuses upon attitudes and beliefs which themselves predict behaviours. Examples include attitudes towards new organisational structures (Gleibs et al. 2010), intergroup contact intentions (Badea et al. 2011) and beliefs about readiness to enter the new group (e.g. Jetten et al. 2008). Whilst such measures are valid in their own right, failing to link them to actual outcomes may be problematic-for instance, in an academic context, whilst feelings of efficacy and academic confidence may be proxies for performance in higher education, there is still considerable variation between confidence and attainment. Similarly, beliefs about social mobility may or may not be reflected by educational attainment which facilitates such mobility. To address this gap, the current study utilised actual attainment data to test the role of incompatibility between two identities - those of being a student and a member of one's ethnic group. It does so in the context of higher education in the UK.

In summary, the current research aimed to explore social identity incompatibility more deeply by developing a measure of both practical and identity incompatibility, and then observing prospective effects of each dimension on both psychological variables and academic performance variables in a population of students entering 
University. It was predicted that BAME students with lower levels of practical and identity incompatibility would not have lower academic attainment relative to nonBAME students, whilst those with higher levels of incompatibility would.

\section{Method}

\subsection{Participants}

Data were collected from two hundred and seventeen level 4 (first year) undergraduates at a modern metropolitan University. Participants were studying a range of social science, media and drama subject areas. Only students enrolled to complete 120 credits (i.e. UK standard full-time course load) were included in the study. International students were not excluded from the sample. Age, gender and ethnic status were derived from a combination of self-report at the point of data collection and, where this was absent, from student records (with the exception of ethnic status which was not gleaned from such records). Self-reported ethnic status was recorded in free text and then categorised as BAME vs. non BAME. Six students (excluded from the study) did not provide ethnicity information. Of the remaining 211 students, the mean age of the sample was 21.15 years $(S D=5.36) .21 .8 \%$ indicated they were male and $78.0 \%$ female; $0.9 \%$ did not indicate their gender. $41.2 \%$ were classed as BAME, $58.8 \%$ as non-BAME and $2.8 \%$ did not provide this information.

\subsection{Design}

A prospective design was employed. Alongside demographic data, measures were taken at the start of the academic year (within three weeks of the start of the students' first term) and consisted of measures of student and ethnic identity, practical and identity incompatibility. At the end of the academic year, average marks achieved across the academic year were gained for each student from the university's registry system.

\subsection{Materials}

\subsubsection{Student identity}

This variable was measured with the following items (drawn from Leach, et al. 2008) on a Likert type scales anchored at 1 (Not at all) and 7 (Very much): 'It is likely that I will often think about the fact that I am a university student', 'The fact that I am university student is likely to be an important part of my identity' and 'Being a university student is likely to be an important part of how I see myself'. These items were given a future tense as university student identities may not have been formed fully at the point of testing. Scale reliability was good (Cronbach's $\alpha=.80$ ). 


\subsubsection{Ethnic identity}

This variable was measured with the following items on the same anchors: 'I often think about the fact that I am a member of my ethnic identity', 'The fact that I am a member of my ethnic group is an important part of my identity' and 'Being a member of my ethnic group is an important part of how I see myself'. Scale reliability was good (Cronbach's $\alpha=.94)$.

\subsubsection{Incompatibility}

Incompatibility was measured using 8 items on 7-point Likert type scales with the same anchors. Item wordings can be seen in Table 1, alongside eventual factor loadings. These items include four items adapted from Ethier and Deaux (1994) and Jetten et al. (2008): 'I worry that my present life is incompatible with my new identity as a university student, 'Sometimes my friends and family don't understand why, as a member of my ethnic group, I want to be a university student' and 'I cannot talk to my friends about what it will be like at university' and 'My family background is incompatible with university life'. We also added an additional new item-'As a member of my ethnic group, being a university student is not encouraged'. Three novel items aiming to measure practical incompatibility in particular were also included in this scale: 'Being a member of my ethnic group means there are practical difficulties in the way of me being a university student', 'Being a member of my ethnic group puts demands on my time which may make it difficult to be a university student' and 'It is difficult to balance the practical demands of being an member of my ethic group and being a university student'. Scale structure for these items can be found in the Incompatibility scale structure section below.

\subsubsection{Social class}

Following Jetten et al. (2008) social class was measured using a single item (Please indicate your social class) on a 8-point (un-numbered) Likert scale anchored at 1 (working class) and 8 (upper class).

\subsubsection{Academic attainment}

For each participant, a mean assessment mark (across all attempted modules) was derived after the final examination boards of the academic session (i.e. when no more attempts at an assessment were possible that academic year). These marks are used to determine progression to the next level of study, but are not used in the calculation of students' final degree classification. 


\subsection{Procedure}

Ethical oversight of this research was provided by London South Bank University's Research Ethic Panel. Data were collected in mass testing sessions at the start of lectures. The first wave of data was collected during the first 3 weeks of students' time at university (e.g. late September, early October). All measures were collected using pen and paper questionnaires. The attainment outcome data was derived from the student record system once the various progression boards had been undertaken (e.g. once the students' final attainment had been ratified by the University).

\section{Results}

\subsection{Incompatibility scale structure}

Principle component analysis was undertaken for the incompatibility items using the sample included in the main analysis. As practical and identity incompatibility may or may not be correlated, a direct oblimin rotation method was employed. The number of factors was not constrained, and factors with Eigenvalues greater than 1 were examined. Two factors meeting these criteria emerged, which were named practical incompatibility and identity incompatibility. Table 1 shows the loadings of each item onto these factors. The two factors accounted for $74.74 \%$ of the variability. $60.82 \%$ was accounted for by the identity dimension, and $13.92 \%$ by the practical dimension. The component correlation was -.55 . Unweighted means for each dimension were calculated for each participant.

\subsection{Relationship between variables}

To examine relationships between the key variables, zero order correlations were undertaken (see Table 2).

\subsection{Differences between BAME and Non BAME students}

\subsubsection{Levels of identity}

A multivariate ANOVA was conducted with participants' student and ethnic identity as dependent variables and BAME status (BAME vs. Non-BAME) as the independent variable. As noted above (see Introduction), age and gender and social class have all been shown in previous literature to independently affect academic attainment. As we were concerned with the unique effects of identity, these factors were included as covariates. For the multivariate model, Gender was not a significant covariate, $F(2$, $183)=.08, p=.921, \eta_{\mathrm{p}}^{2}<.001$. Age was not a significant covariate, $F(2,183)=.06$, $p=.058, \eta_{\mathrm{p}}^{2}=.031$. Social class was a significant covariate, $F(2,183)=4.28, p=.015$, 


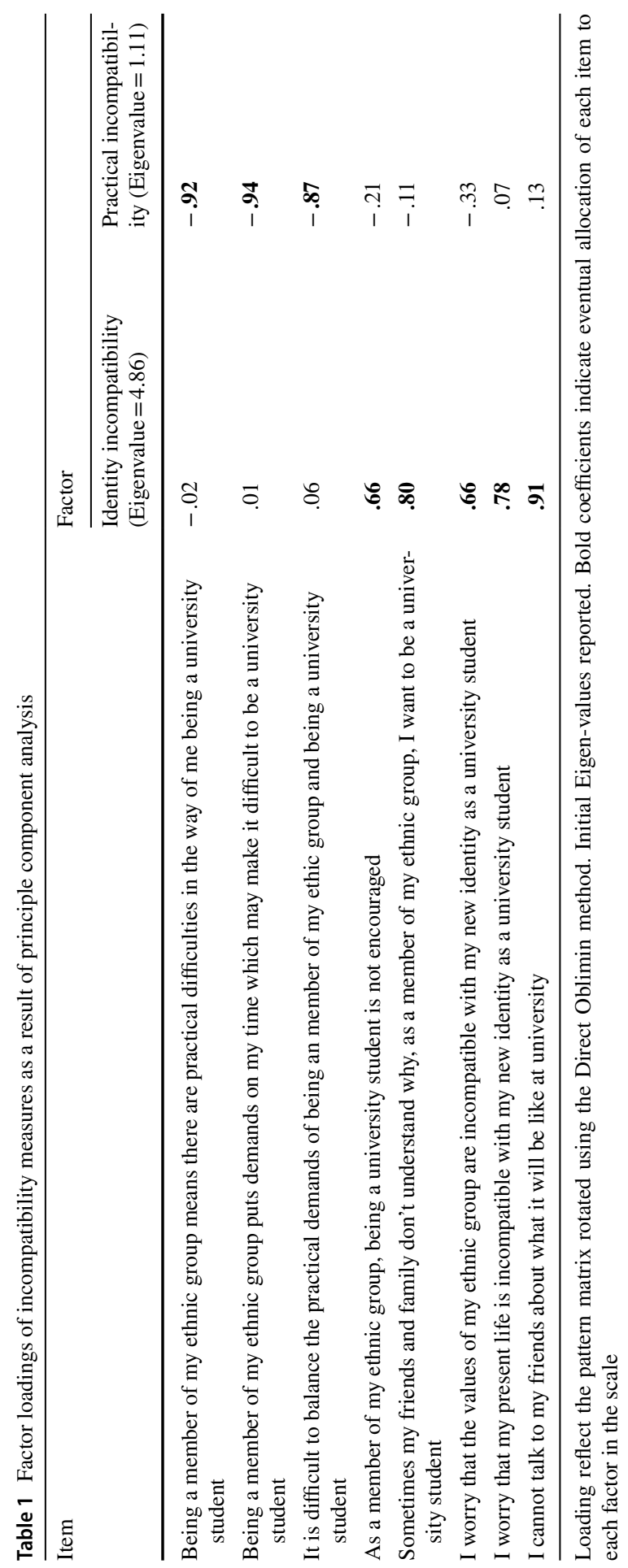




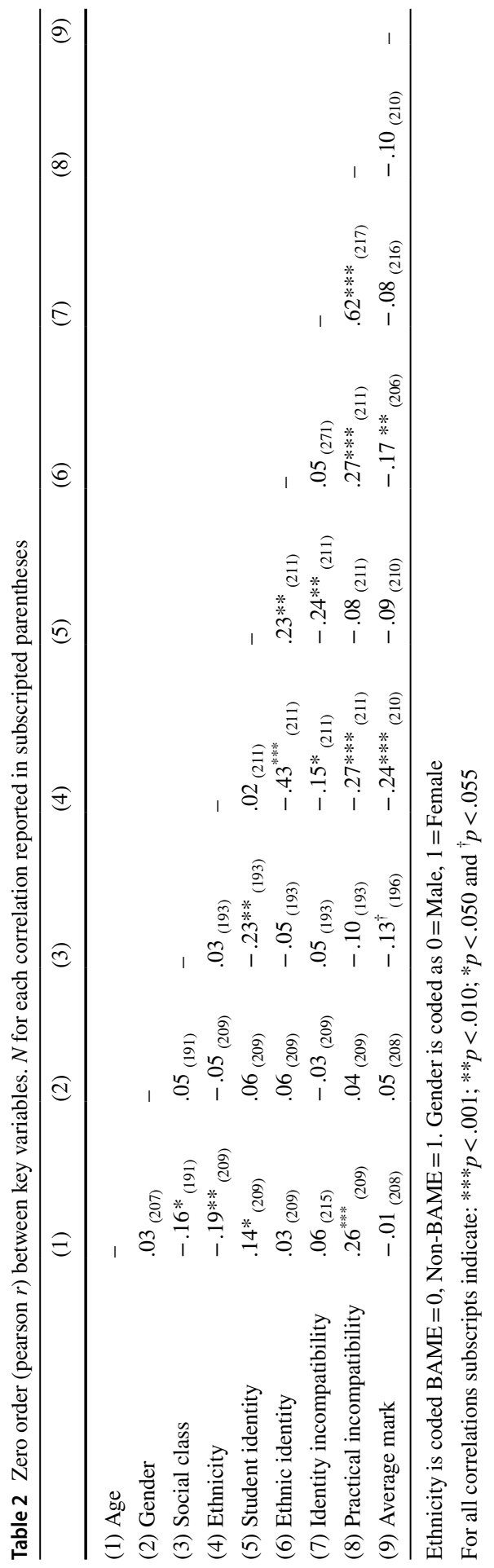


$\eta_{\mathrm{p}}^{2}=.045$. BAME status had an overall effect, $F(2,202)=23.77, p<.001, \eta_{\mathrm{p}}^{2}=.206$, with BAME students having higher overall levels of identity $(M=4.67, S D=1.49)$ than non-BAME students $(M=3.99, S D=1.37)$.

\subsubsection{Student identity}

Examination of the associated univariate tests associated with the above analysis revealed that, for student identity $(M=5.27, S D=1.27)$, gender was not a significant covariate, $F(1,184)=.16, p=.692, \eta_{\mathrm{p}}^{2}<.001$. Age was not a significant covariate, $F(1,184)=1.84, p=.177, \eta_{\mathrm{p}}^{2}=.010$. Social class was a significant covariate, $F(1,184)=8.60, p<.001, \eta_{\mathrm{p}}^{2}=.045$. The main effect of BAME status (BAME; $M=5.23, S D=1.38$ vs Non BAME; $M=5.29, S D=1.19$ ) was not significant, $F(1,184)=.48, p=.489, \eta_{\mathrm{p}}^{2}<.001$.

\subsubsection{Ethnic identity}

As above, univariate tests on ethnic identity were undertaken. Gender was not a significant covariate, $F(1,184)<.001, p=.993, \eta_{\mathrm{p}}^{2}<.001$. Age was also not a significant covariate, $F(1,184)=2.47, p=.118, \eta_{\mathrm{p}}^{2}=.010$. Social class was not a significant covariate, $F(1,184)=.53, p=.467, \eta_{\mathrm{p}}^{2}=.003$. The main effect of BAME status was significant, $F(1,184)=41.80, p<.001, \eta_{\mathrm{p}}^{2}=.185$. BAME students had higher mean levels of ethnic identity $(M=4.15, S D=1.60)$ than did non-BAME students $(M=2.68, S D=1.55)$.

\subsubsection{Levels of incompatibility}

A multivariate ANOVA with the same independent and covariates as above was conducted with participants' practical and identity incompatibility as the dependent variables. For the multivariate model, gender was not a significant covariate, $F(2$, $183)=0.67, p=.512, \eta_{\mathrm{p}}^{2}=.007$. Age was a significant covariate, $F(2,183)=7.62$, $p<.001, \eta_{\mathrm{p}}^{2}=.077$. Social class was not a significant covariate, $F(2,183)=1.18$, $p=.310, \eta_{\mathrm{p}}^{2}=.010$. BAME status had an overall effect, $F(2,183)=3.66, p=.028$, $\eta_{\mathrm{p}}^{2}=.039$. Overall incompatibility was on average higher for BAME students $(M=1.86, S D=1.23)$ than for non-BAME students $(M=1.44, S D=0.77)$.

\subsubsection{Identity incompatibility}

A univariate ANOVA revealed that gender was not a significant covariate $F(1,184)=0.09, p=.771, \eta_{\mathrm{p}}^{2}<.001$. Age was not a significant covariate $F(1$, $184)=.37, p=.547, \eta_{\mathrm{p}}^{2}=.02$. Social class was not a significant covariate, $F(1$, $184)=0.47, p=.493, \eta_{\mathrm{p}}^{2}=.003$. The main effect of BAME status was significant, $F(1,183)=3.97, p=.048, \eta_{\mathrm{p}}^{2}=.021$. BAME students had higher identity incompatibility $(M=1.69, \mathrm{SD}=1.21)$ than did non-BAME students $(M=1.39, S D=0.68)$. 


\subsubsection{Practical incompatibility}

A univariate ANOVA revealed that gender was not a significant covariate. $F(1$, $184)=0.55, p=.461, \eta_{\mathrm{p}}^{2}=.003$. Age was a significant covariate, $F(1,183)=12.12$, $p=.001, \eta_{\mathrm{p}}^{2}=.062$. Social class was not a significant covariate, $F(1,184)=0.50$, $p=.478, \eta_{\mathrm{p}}^{2}=.003$. The main effect of BAME status was significant, $F(1,184)=7.09$, $p=.008, \eta_{\mathrm{p}}^{2}=.037$. BAME students had higher practical incompatibility $(M=2.03$, $S D=1.24)$ than did non-BAME students $(M=1.49, S D=0.86)$.

\subsubsection{Academic performance}

An ANOVA was conducted on participants' average mark, with BAME status as the independent variable and age and gender and social class as covariates. Neither age $\left(F(1,183)=0.52, p=.472, \eta_{\mathrm{p}}^{2}=.003\right)$ nor gender $(F(1,183)=0.52, p=.472$, $\left.\eta_{\mathrm{p}}^{2}=.003\right)$ nor social class, $\left(F(1,183)=3.61, p=.059, \eta_{\mathrm{p}}^{2}=.019\right)$ were significant covariates. BAME students had on average lower $(M=58.39, \mathrm{SD}=7.17)$ mean marks than did non-BAME students $(M=62.41, S D=6.39), F(1,183)=17.71$ $p<.001, \eta_{\mathrm{p}}^{2}=.088{ }^{1}$

In summary, once effects of age, gender and social class were accounted for, BAME students had similar levels of student identity to non-BAME students. However, they also had higher levels of ethnic identity, identity and practical incompatibility and lower marks than did non-BAME students.

\subsection{Effects of BAME status and incompatibility on performance}

To test whether the difference in BAME and non-BAME performance is dependent on levels of practical and identity incompatibility we constructed a moderation model using the process macro provided by Hayes (2013, Model 2). This model tested the relationship between BAME status $(0=$ BAME, $1=$ non-BAME) and average mark attained. The moderating effects of both practical and identity incompatibility (and the resulting interaction terms) were also tested. An initial model including age, gender and social class as covariates was constructed. However, none of these latter factors were significant covariates at $\alpha=.05$. Thus, a model without covariates was constructed. One thousand bootstrap samples were taken, and $95 \%$ confidence intervals are reported (with confidence interval ranges not including 0 indicating significance at the $p<.05$ level).

The overall model included 210 participants and was significant, $R^{2}=.09, F(5$, $204)=4.14, p=.001)$. BAME status related to performance, with non-BAME students achieving higher marks than BAME students, $\left(b_{1}=8.05, t=3.92\right.$, CIs $=4.01$, 12.08). Identity incompatibility did not directly affect marks, $b_{2}=.23, t=0.29$,

\footnotetext{
${ }^{1}$ In the UK mark classification system, this represents a notable difference in that, on average, BAME students were achieving a lower level degree (Lower Second Class Honours) than non-BAME (Higher Second Class Honours). A Higher Second Class degree is also a common entry threshold for UK postgraduate study.
} 
Table 3 Effects of BAME status on average marks, according to levels of practical and identity incompatibility. $95 \%$ confidence intervals in parentheses

\begin{tabular}{llll}
\hline \multicolumn{4}{c}{ Identity incompatibility } \\
\cline { 2 - 4 } & Low & Medium & High \\
\hline Practical incompatibility & & \\
Low & $5.06^{* * *}$ & $3.99^{* *}$ & 2.06 \\
& $(2.65,7.46)$ & $(1.37,6.59)$ & $(-2.18,6.30)$ \\
Medium & $4.25^{* * *}$ & $3.18^{* *}$ & 1.26 \\
& $(1.95,6.56)$ & $(1.23,5.13)$ & $(-1.98,4.49)$ \\
High & 3.06 & 1.99 & 0.07 \\
& $(-0.75,6.68)$ & $(-1.06,5.05)$ & $(-2.87,3.11)$ \\
\hline
\end{tabular}

Positive effects represent non-BAME students achieving higher marks. Effects are calculated at Low (M-1SD) Medium (M) and High (M +1SD) levels of each moderator

$* * * p<.001 ; * * p<.01$

CIs $=-1.36,1.82)$ nor did practical identity $\left(b_{3}=.34, t=0.41\right.$, CIs $=-.1 .30$, 1.97). The interaction between BAME status and identity incompatibility was not significant, $\left(b_{4}=-1.90, t=1.55\right.$, CIs $\left.=-4.32,0.52\right)$ nor was the interaction between BAME status and practical identity incompatibility $\left(b_{5}=-1.08, t=0.96\right.$, CIs $=-3.31,1.14)$. The combined effects of these interactions, however, increased the $R^{2}$ of the model, $R^{2}$ change $=.03, F(2,204)=3.66, p=.03$. Thus, we proceeded with testing simple effects within the model. As can be seen in Table 3, Non-BAME students outperformed BAME students when levels of both practical and identity incompatibility were low or medium. In contrast, when students had high levels of either identity or practical incompatibility present, no attainment difference was observed.

In summary, BAME students had equal levels of student identity to non-BAME students, but higher levels of ethnic identity. They also typically experienced higher levels of both practical and identity incompatibility. Finally, BAME students had lower attainment than did non-BAME students. Both practical and identity incompatibility appeared to moderate this effect. However, contrary to predictions, it was only when levels of both of these moderators were low or medium that BAME students attained lower marks than their non-BAME peers.

\section{Discussion}

\subsection{Discussion of findings}

Many life transitions present challenges to individuals. One transition which has been the focus of considerable research is entry into higher education. As a source of social mobility and a predictor of a variety of positive outcomes (Sutton Trust 2015) it is important to understand why some individuals adjust well and others do not. Previous research (e.g. Ethier and Deaux 1994; Jetten et al. 2008) has looked at the role of incompatibility between past and new identities. Typically, this has 
shown that higher levels of incompatibility are linked to less positive psychological outcomes. However, it has been limited in that the dimension of incompatibility is not well defined, and actual performance data has not been consistently examined. The current study represents the first attempt to differentiate between two dimensions of incompatibility surrounding ethnicity. Practical incompatibility represents difficulties which are tangible-demands ones' ethnic identity places on time and other resources which are incompatible with the demands of other identities. In contrast, identity incompatibility reflects incompatibility in beliefs, norms and the ability to share views and experiences from one identity with people connected to another. This was explored by tracking levels of each compatibility amongst a cohort of students (both BAME and non-BAME) entering higher education. As predicted, incompatibility measures in the current study loaded onto two distinct but related factors-which appeared to reflect practical and identity incompatibility. This new operationalisation of identity incompatibility is important in that it highlights that practical and identity- based concerns are distinct-and as such that addressing practical issues associated with a student's background will not automatically also impact identity-based ones. Thus, intervention designed to support particular demographics of students should be clear on what incompatibility they are targeting (and why) to be most effective.

A further aim of the current study was to observe the effect that both practical and identity incompatibility had on the relationship between BAME status and academic attainment. Previous work (e.g. Murtagh et al. 2016; Reay et al. 2002; Richardson 2012; Ridley 2007) has reported lower attainment from BAME students relative to their non-BAME peers. We observed the same pattern of results. However, when examining whether both dimensions of incompatibility moderated the effect of ethnicity on attainment, we found that non-BAME students only outperformed BAME students when practical and identity incompatibility were both at low or medium levels. When either incompatibility was higher, non-BAME students performed less well and at a similar level to BAME students. Importantly, this also means that lower practical and identity incompatibility did not increase non-BAME performance. In summary, when levels of incompatibility are low, a commonly observed attainment gap is found. However, when levels of incompatibility are higher, nonBAME students are affected more (to the extent they perform equivalent to BAME students, who attain less). In essence, although BAME students entering HE experience greater levels of incompatibility, it is non-BAME students who are adversely affected by it. More broadly, this hypothesis is particularly intriguing as it suggests identity incompatibility may affect all groups in some contexts and is not a result of minority status. It also suggests that either (i) some developmental processes (e.g. prior experience) may alter responses to such incompatibility and/or, (ii) not all members of a group are affected. These findings are both novel and important as they suggest that some students may be more at risk of negative impacts of identity incompatibility than others. Moreover, they also suggest that both BAME and nonBAME students may need significant support during the transitioning to higher education studies to fulfil their potential.

This study has a number of theoretical and practical implications. Most importantly, it shows, for the first time, that incompatibility is likely to be a complex 
psychological dimension with a variety of sub-components. It also suggests that incompatibility may affect BAME students and non-BAME students differently. The unexpected finding that BAME status only generated an attainment gap under conditions of low and medium incompatibility could be explained by placing both BAME and non-BAME transitions into context. BAME students may experience a sense of incompatibility in a wider range of situations prior to entering Higher Education (e.g. Further Education [High School] settings, work environments, etc.,) than do non-BAME students. Thus, experiencing incompatibility may be a novel experience to non-BAME students to a greater extent than BAME students. One possibility is that, as a result, BAME students develop more resilience to incompatibility than do non-BAME students. When levels of incompatibility are low, a commonly observed attainment gap is found. Thus, when levels of compatibility are higher, non-BAME students display more adverse effects (to the extent they perform equivalent to BAME students, who attain less). Speculating further, if greater prior experience of identity incompatibility were found to inoculate BAME students from its adverse effects, it is possible that BAME students experience lower levels of anxiety than non-BAME students when identity incompatibility is high. Work from the stereotype threat perspective (which suggests anxiety that one may confirm negative stereotypes about one's group can lead to cognitive load which itself impairs performance, e.g. Steele 1992, 1997) indicates this may help to improve performance, to the extent that anxiety generated as a result of membership of negatively stereotyped groups has been linked to lower levels of attainment in BAME students (Osborne 2001; Martiny et al. 2015).

\subsection{Limitations and future research}

The current study has a number of limitations which suggest avenues for further research. The current findings are exploratory and should only be applied to practice tentatively until the evidence base is expanded. However, when combined with previous research on incompatibility they do suggest that initial efforts at reducing incompatibility may benefit students-although perhaps non-BAME students to a greater extent. As both practical and identity incompatibility play a role in moderating attainment, the current research suggests that interventions must address both forms of incompatibility to be effective. If some form of resilience to incompatibility was present in the current study, identifying and harnessing the related psychological processes may well provide an effective tool for helping students from all backgrounds. A number of additional factors beyond the scope of the study may also ameliorate or exacerbate the observed effects. For example, STEM (science, technology, engineering and mathematics) students may have identities which differ in strength and meaning to non-STEM students (both were included in the current sample). Membership of student social/support societies may buffer stress responses, and both the levels of, and responsibility for, tuition fees may also change the meaning of identities and the psychological and academic attainment impact of their interaction. In this vein, it is also worth noting that the current research utilised a relevantly superordinate identity (one which encompasses others, see Tajfel 
and Turner 1979)—being 'a student'. More granular identities (i.e. 'an arts student', a 'nursing student', etc.), or dual identities ('African-American') may operate differentially, to the extent the contents differ. However, regardless of the content, the level of incompatibility between a given set of two identities could reasonably be assumed to have similar effects to those observed between another two.

Methodologically, the scale devised was sensitive to changes in incompatibilities, and such changes were systematically linked to changes in other established scales. However, a number of floor effects were observed. Future research should devise more sensitive measures (perhaps by measuring levels of both compatibility and incompatibility) to address this. Despite this limitation, it is notable that having incompatibility at any level appeared to relate to, or even influence, other outcome variables such as levels of identity and academic attainment, suggesting that the dimensions are meaningful even if not captured completely with the current instrument.

\section{Conclusion}

In summary, this study confirms previous work that suggests identity incompatibility is an important predictor of psychological outcomes during periods of transition. It also suggests that identity incompatibility can also affect material outcomes such as academic performance. Contrary to expectations, an attainment gap was observed between BAME and non-BAME students only when levels of either incompatibility was moderate or low. These findings advance our theoretical understanding of how identity and practical compatibility are operationalised in student populations and the impact they have on attainment amongst different groups. In doing so, they highlight the need to be sensitive to the transition needs and challenges of both BAME and non-BAME students.

Open Access This article is distributed under the terms of the Creative Commons Attribution 4.0 International License (http://creativecommons.org/licenses/by/4.0/), which permits unrestricted use, distribution, and reproduction in any medium, provided you give appropriate credit to the original author(s) and the source, provide a link to the Creative Commons license, and indicate if changes were made.

\section{References}

Amiot, C. E., de la Sablonnière, R., Terry, D. J., \& Smith, J. R. (2007). Integration of social identities in the self: Toward a cognitive-developmental model. Personality and Social Psychology Review, 11, 364-388. https://doi.org/10.1177/1088868307304091.

Amiot, C. E., Terry, D. J., \& McKimmie, B. M. (2012). Social identity change during an intergroup merger: The role of status, similarity, and identity threat. Basic and Applied Social Psychology, 34, 443-455. https://doi.org/10.1080/01973533.2012.712016.

Badea, C., Jetten, J., Iyer, A., \& Er-Rafiy, A. (2011). Negotiating dual identities: The impact of groupbased rejection on identification and acculturation. European Journal of Social Psychology, 41, 586-595. https://doi.org/10.1002/ejsp.786. 
Bliuc, A. M., Ellis, R. A., Goodyear, P., \& Hendres, D. M. (2011). Understanding student learning in context: Relationships between university students' social identity, approaches to learning, and academic performance. European Journal of Psychology of Education, 26, 417-433. https://doi. org/10.1007/s10212-011-0065-6.

Broeke, S., \& Nicholls, T. (2007). Ethnicity and degree attainment. Retrieved from http://mpra.ub.unimuenchen.de/35284/. Accessed 2nd June 2014.

Buckingham, S. A., Frings, D., \& Albery, I. P. (2013). Group membership and social identity in addiction recovery. Psychology of Addictive Behaviors, 27, 1132-1140. https://doi.org/10.1037/a0032480.

Bule, B., \& Frings, D. (2015). The role of group membership continuity and multiple memberships on mental well-being amongst post-operative stoma patients. Psychooncology, 25, 726-728. https://doi. org/10.1002/pon.4006.

Cruwys, T., Dingle, G. A., Haslam, C., Haslam, S. A., Jetten, J., \& Morton, T. A. (2013). Social group memberships protect against future depression, alleviate depression symptoms and prevent depression relapse. Social Science and Medicine, 98, 179-186. https://doi.org/10.1016/j.socsc imed.2013.09.013.

Cruwys, T., Haslam, S. A., Dingle, G. A., Jetten, J., Hornsey, M. J., Chong, E. M. D., et al. (2014). Feeling connected again: Interventions that increase social identification reduce depression symptoms in community and clinical settings. Journal of Affective Disorders, 159, 139-146. https://doi. org/10.1016/j.jad.2014.02.019.

Ethier, K. A., \& Deaux, K. (1994). Negotiating social identity when contexts change: Maintaining identification and responding to threat. Journal of Personality and Social Psychology, 67, 243-251. https ://doi.org/10.1037//0022-3514.67.2.243.

Frings, D., \& Albery, I. P. (2015). The social identity model of cessation maintenance: Formulation and initial evidence. Addictive Behaviors, 44, 35-42. https://doi.org/10.1016/j.addbeh.2014.10.023.

Frings, D., \& Albery, I. P. (2016). The social identity model of cessation maintenance. In S. Buckingham \& D. Best (Eds.), Addiction, behavioural change and social identity. London: Routledge.

Gleibs, I., Haslam, C., Haslam, S., \& Jones, J. (2011a). Water clubs in residential care: Is it the water or the club that enhances health and well-being? Psychology \& Health, 26, 1361-1377. https://doi. org/10.1080/08870446.2010.529140.

Gleibs, I. H., Haslam, C., Jones, J. M., Haslam, S. A., McNeill, J., \& Connolly, H. (2011b). No country for old men? The role of a "Gentlemen's Club" in promoting social engagement and psychological well-being in residential care. Aging \& Mental Health, 15, 456-466. https://doi.org/10.1080/13607 863.2010.536137.

Gleibs, I. H., Mummendey, A., \& Noack, P. (2008). Predictors of change in postmerger identification during a merger process: A longitudinal study. Journal of Personality and Social Psychology, 95, 1095-1112.

Gleibs, I. H., Noack, P., \& Mummendey, A. (2010). We are still better than them: A longitudinal field study of ingroup favouritism during a merger. European Journal of Social Psychology, 40, 819-836. https://doi.org/10.1002/ejsp.652.

Haslam, S., \& O’Brien, A. (2005). Taking the strain: Social identity, social support, and the experience of stress. British Journal of Social Psychology, 44, 355-370. https://doi.org/10.1348/014466605X 37468.

Haslam, S., \& van Dick, R. (2010). A social identity approach to workplace stress. In D. De Cremer, R. van Dick, \& K. Murnighan (Eds.), Social psychology and organizations (pp. 325-352). New York: Routledge.

Hayes, A. F. (2013). Introduction to mediation, moderation, and conditional process analysis: A regression-based approach. New York: Guilford Press.

Heath, A. F., Rothon, C., \& Kilpi, E. (2008). The second generation in Western Europe: Education, unemployment, and occupational attainment. Annual Review of Sociology, 34, 211-235.

Héliot, Y., Gleibs, I. H., Coyle, A., Rousseau, D. M., \& Rojon, C. (2019). Religious identity in the workplace: A systematic review, research agenda, and practical implications. Human Resource Management, 58, 1-21.

Hermansen, A. S. (2016). Moving up or falling behind? Intergenerational socioeconomic transmission among children of immigrants in Norway. European Sociological Review, 32, 675-689.

Iyer, A., Jetten, J., Tsivrikos, D., Postmes, T., \& Haslam, S. A. (2009). The more (and the more compatible) the merrier: Multiple group memberships and identity compatibility as predictors of adjustment after life transitions. British Journal of Social Psychology, 48, 707-733. https://doi. org/10.1348/014466608X397628. 
Jetten, J., Haslam, C., \& Haslam, S. A. (2012). The social cure: Identity, health and well-being (J. Jetten, C. Haslam, \& S. A. Haslam, Eds.). Hove: Psychology Press.

Jetten, J., Iyer, A., Tsivrikos, D., \& Young, B. M. (2008). When is individual mobility costly? The role of economic and social identity factors. European Journal of Social Psychology, 38, 866-879. https:// doi.org/10.1002/ejsp.471.

Jones, J. M., Haslam, S. A., Jetten, J., Williams, W. H., Morris, R., \& Saroyan, S. (2011). That which doesn't kill us can make us stronger (and more satisfied with life): The contribution of personal and social changes to well-being after acquired brain injury. Psychology \& Health, 26, 353-369. https:// doi.org/10.1080/08870440903440699.

Jones, J. M., \& Jetten, J. (2011). Recovering from strain and enduring pain: Multiple group memberships promote resilience in the face of physical challenges. Social Psychological and Personality Science, 2, 239-244. https://doi.org/10.1177/1948550610386806.

Jones, J. M., Williams, W. H., Jetten, J., Haslam, S. A., Harris, A., \& Gleibs, I. H. (2012). The role of psychological symptoms and social group memberships in the development of post-traumatic stress after traumatic injury. British Journal of Health Psychology, 17, 798-811. https://doi.org/10.111 1/j.2044-8287.2012.02074.x.

Labi, A. (2015). Placing student success at the center of state higher education finance policy. Lumina Issue Papers. Retrieved April 22, 2016. http://eric.ed.gov/?id=ED561331.

Leach, C. W., Van Zomeren, M., Zebel, S., Vliek, M. L., Pennekamp, S. F., Doosje, B., et al. (2008). Group-level self-definition and self-investment: A hierarchical (multicomponent) model of ingroup identification. Journal of Personality and Scial Psychology, 95, 144-165. https://doi. org/10.1037/0022-3514.95.1.144.

Martiny, S. E., Gleibs, I. H., Parks-Stamm, E. J., Martiny-Huenger, T., Froehlich, L., Harter, A. L., et al. (2015). Dealing with negative stereotypes in sports: The role of cognitive anxiety when multiple identities are activated in sensorimotor tasks. Journal of Sport and Exercise Psychology. https://doi. org/10.1123/jsep.2014-0284.

Martiny, S. E., Mok, S. Y., Deaux, K., \& Froehlich, L. (2014). Effects of activating negative stereotypes about Turkish-origin students on performance and identity management in German high Schools. Revue Internationale de Psychologie Sociale, 27, 205-225.

Mok, S. Y., Martiny, S. E., Gleibs, I. H., Deaux, K., \& Froehlich, L. (2017). The interaction of vertical collectivism and stereotype activation on the performance of Turkish-origin high school students. Learning and Individual Differences, 56, 76-84.

Mok, S. Y., Martiny, S. E., Gleibs, I. H., Keller, M. M., \& Froehlich, L. (2016). The relationship between ethnic classroom composition and Turkish-origin and German students' reading performance and sense of belonging. Frontiers in Psychology, 7, 1071.

Mpofu, E., \& Oakland, T. (2001). Predicting school achievement in Zimbabwean multiracial schools using Biggs' Learning Process Questionnaire. South African Journal of Psychology, 31(3), 20-28. https://doi.org/10.1177/008124630103100303.

Murtagh, S., Ridley, A., Frings, D., \& Kerr-Pertic, S. (2016). First-year undergraduate induction: Who attends and how important is induction for first year attainment? Journal of Further and Higher Education. https://doi.org/10.1080/0309877X.2016.1159288.

Osborne, J. W. (2001). Testing stereotype threat: Does anxiety explain race and sex differences in achievement? Contemporary Educational Psychology, 26, 291-310. https://doi.org/10.1080/01443 410601069929.

Reay, D. J., Davies, M., \& Ball, S. J. (2002). It's taking me a long time but I'll get there in the end: Mature students on access courses and higher education choice. British Educational Research Journal, 28, 5-19. https://doi.org/10.1080/01411920120109711.

Richardson, J. T. (2008). The attainment of ethnic minority students in UK higher education. Studies in Higher Education, 33, 33-48. https://doi.org/10.1080/03075070701794783.

Richardson, J. T. E. (2012). The attainment of White and ethnic minority students in distance education. Assessment \& Evaluation in Higher Education, 37, 393-408. https://doi.org/10.1080/02602 938.2010.534767.

Ridley, A. M. (2007). Approaches to learning, age, ethnicity and assessment. Implications for widening participation. Psychology Teaching Review, 13, 3-13.

Schnell, P., \& Azzolini, D. (2015). The academic achievements of immigrant youths in new destination countries: Evidence from southern Europe. Migration Studies, 3(2), 217-240.

Steele, C. M. (1992). Race and the schooling of Black Americans. The Atlantic Monthly, 269(4), 68-78. 
Steele, C. M. (1997). A threat in the air: How stereotypes shape intellectual identity and performance. American Psychologist, 52, 613. https://doi.org/10.1037/0003-066X.52.6.613.

Stevenson, J., \& Whelan, P. (2013). Synthesis of US literature relating to the retention, progression, completion and attainment of black and minority ethnic (BME) students in HE. York: Higher Education Academy.

Sutton Trust. (2015). Improving social mobility through education. Online report retrieved from http:// www.suttontrust.com/wp-content/uploads/2014/06/SUTTON-TRUST-BROCHURE-2014-2015.pdf on 22nd June 2016.

Tajfel, H., \& Turner, J. (1979). An integrative theory of intergroup conflict. In W. Austin \& S. Worchel (Eds.), Psychology of intergroup relations (pp. 33-47). Chicago: Nelson-Hall.

Woolf, K., McManus, I. C., Potts, H. W., \& Dacre, J. (2013). The mediators of minority ethnic underperformance in final medical school examinations. British Journal of Educational Psychology, 83, 135-159. https://doi.org/10.1111/j.2044-8279.2011.02060.x.

Ysseldyk, R., Haslam, S. A., \& Haslam, C. (2013). Abide with me: Religious group identification among older adults promotes health and well-being by maintaining multiple group memberships. Aging \& Mental Health, 17, 869-879. https://doi.org/10.1080/13607863.2013.799120.

Publisher's Note Springer Nature remains neutral with regard to jurisdictional claims in published maps and institutional affiliations.

Daniel Frings is a Professor of Social Psychology at London South Bank University in the Division of Psychology. His main research interest is exploring how social identities affect our experience of stressful events and life transitions. He has particular foci around addiction and mental health.

Ilka H. Gleibs is an Associate Professor in Social and Organisational Psychology at the London School of Economics in the Department of Psychological and Behavioral Science. Her main research focus is on social identity dynamics and how they influence people's lives.

Anne M. Ridley's research interests are factors predicting student success with a view to developing appropriate support, and suggestibility, eyewitness memory and vulnerable witnesses. She was an Associate Professor in the Division of Psychology at London South Bank University and is now retired. 